of these means. It appeared that her sufferings were exacerbated by the want of a free opening for the discharge of the matter. I therefore, on the 15th, with the advice of Mr. Andrews, introduced a probe-pointed bistoury, and divided the pharynx upwards to the extent of at least threequarters of an inch, by which a free exit was given to the matter. This relieved her at once, and from this moment she began to mend, the discharge being free, and becoming gradually odourless, and a small quantity of curdy matter escaping with the discharge. She was in the habit of squeezing the matter out with her hands firmly pressed around the neck, and thus has continued to evacuate the cyst. Previously to the enlargement of the wound by the bistoury, the extremity of a sound was passed into the wound; and this, by the employment of considerable force, was made to project under the right sterno-cleido-mastoideus muscle; and it became a question whether an opening ought not to be made upon the sound through the muscle, rather than to enlarge the pharyngeal opening; but the depth of parts to be divided, and the close proximity to the carotid sheaths, together with the anticipated difficulty of keeping the opening patent, induced me to adopt the latter alternative.

May 18th.-She has left the hospital completely cured.

\section{Griginal zapers.}

\section{ON ULCERATION OF 'THE CERVIX UTERI ACCOMPANYING UTERINE POLYPI.}

\section{BY HENRY BENNET, M.D., \\ OBSTETRIC PHYSICIAN TO THE WESTERN GENGRAL DISPENSARY, KTC.}

(Read before the Harveian Society, April, 1847.)

IN a former communication, published in The LanceT of July, 1845, I drew the attention of the profession to the fact of uterine polypi being frequently accompanied by ulceration of the mucous membrane of the cervix uteri, and of its cavity. I then stated, likewise, that further investigations would, in all probability, show this complication to be very frequent. These views, which my subsequent experience has entirely confirmed, have lately received the fullest sanction and support from one of the most eminent uterine pathologists of the present day-Dr. Montgomery, of Dublin. In a very interesting and valuable article on uterine polypus, which appeared in the last August number of The Dublin Quarterly Journal, Dr. Montgomery has given the listory of several patients in whom the two diseases coëxisted, the ulceration having evidently been produced by the presence of the polypus. I have recently met with a case of this description, which has presented so many important features, both with reference to the antecedents, the diagnosis, and the treatment, that $I$ think it worthy of being placed on record.

In May, 1846, I was requested to see, in consuitation, a lady, aged thirty-nine, who had been suffering for many years under obscure uterine disease. From the gentleman in attendance, and from the patient herself, I elicited the following details:-Menstruated rather early in life, about twelve or thirteen; she enjoyed good health as a girl, although always rather delicate; at eighteen she went abroad, and settled in South America, in a tropical climate. Here she married, and had two children within the first few years of her marriage. The labours were ordinary, and were not followed by any untoward symptoms. About the age of twenty-five, the menses, which had previously only lasted four or five days, began to be more abundant and more prolonged; this state of things became gradually more and more marked, the flow of blood often lasting fourteen, twenty, or more days, withont, however, being excessively abundant, except during the first three or four. She also experienced severe and continued pain in the lower part of the back, and slight pain in the ovarian regions, especially the left, and had a white vaginal discharge. The uterus was examined per vaginam; the only lesions, however, which were detected, were slight hardness and tenderness of the cervix.

Every known means of arresting uterine hremorrhage were resorted to, but without avail. As the general health was rapidly giving way under the influence of the continued hæmorrhage and uterine irritation, and as it was thought that a tropical climate might be the cause of the obstinate resistance of the morbid symptoms to all remedial agents, she was at last ordered home to Europe. She was then
thirty-one years of age. The change of climate, however, brought no alleviation in the hæmorrhage and local pains. The former continued to occur at each monthly period; the flow of blood sometimes continuing from one period to the other. During the eight years that had elapsed when I saw this lady since her return to this country, she had been nearly always under medical treatment. The uterus was always examined with the hand by the various practitioners who attended her, but never with the speculum, instrumental examination being invariably deemed unnecessary; and different opinions had been given. All who were consulted, however, agreed in considering the womb inflamed, and in recommending antiphlogistic treatment. In consequence of these ideas, she was cupped in the loins some score times or more, and was quite drained by leeches applied to the hypogastrium and vulva. The antiphlogistic measures thus pursued, $\grave{a}$ outrance, appeared, however, only still further to debilitate the general health, which became more and more affected. At one time, the solid nitrate of silver was applied to the cervix uteri through a tube, without a speculum being used, daily, for six weeks. This treatment appeared to lessen the duration and amount of the hremorrhage for a few months, as had occasionally been the case with other means, but it then returned as before. A few years ago, the medical gentleman who had attended the lady in America, returned to England, and, on examining digitally, found that the cervix, which was hard and closed when he last saw her, had become open and soft. This change in the state of the cervix had evidently occurred recently, as it had been noticed by the practitioner in attendance, who told the patient that he was afraid it was a forerunner of cancerous degenerescence. Her medical friend, by whom I was called in, told me that he then thought the change was the result of the excessive loss of blood which she had suffered, both from the treatment and the disease.

The above account was by no means encouraging, and I much feared that I should find the patient labouring under some organic disease of the uterus. The complexion presented the pale, rather sallow hue, which we find in the ulcerative stage of uterine cancer; but this cachectic hue is also met with in severe chronic inflammation of the uterus, and in obstinate flooding as well as in cancerous disease. At the same time, the lengthened duration of the morbid symptoms proved that they could not all along have depended on cancerous disease, even if it then existed. On examining digitally, I found the vagina lax, and very sensitive; the cervix low, very retroverted, voluminous, and indurated, but perfectly smooth and even; the os so open as freely to admit two-thirds of the first phalange of the index. The kind of small cavity into which the finger thus penetrated, was soft and fungous to the touch; the uterus was rather voluminous and sensitive to pressure, but presented no nodosities or inequalities. The hypertroplied state of the cervix, and the patent velvety condition of the os, showing at once that there was inflammation of the cervix, and ulceration around and in its os, I explained the necessity of an instrumental examination. This was at once assented to, and with a large bivalve speculum, and in a good light, I raised the retroverted cervix, and expanding the blades to their fullest extent, brought the cervix and open os fairly into view. I then at once saw the cause of the hitherto unexplained uterine sufferings of the patient. Just between the separated lips of the enlarged cervix was a small vascular polypus, about the size of a hazel nut, occupying the cavity of the os, and merely showing its anterior extremity on the blades of the bivalve speculum being expanded. If they were allowed to approximate even partially, the hypertrophied lips of the cervix closed over the os so as to conceal it and the contained polypus. I ascertained, by means of the uterine probe, that the polypus proceeded from the uterine edge of the cavity of the neck, above an inch from the os cervicis. It was connected with the point from which it originated by a soft pedicle. The cavity of the uterine neck was much dilated, and all that portion of it that was accessible to the eye was ulcerated. The ulceration occupied the entire contour of the os for a few lines beyond the point reached by the head of the polypus. The latter vas very red and vascular, and so soft as to pit deeply under the slightest pressure. The circumstance of its being thus embedded, as it were, in the cavity of the os, and its softness, accounted at once for its not being perceptible to the touch. The fingers, on examining the os uteri, merely felt a small, soft, fungous cavity, representing the apex only of the polypus, and the surrounding ulcerated tissues. The cervix itself was much enlarged, red, and inflamed, and so much retroverted as to be brought into view with some difficulty. It was not without trouble that I succeeded in persuading the patient, even with the corrobora- 
tive evidence of her medical friend, that she really was suffering from the presence of a small uterine tumour, that had probably been there for many years, and had thus occasioned the hæmorrhages and uterine inflammation, by which her life had been so long embittered. Having family matters to arrange, it was determined that the extirpation of the polypus should be deferred for a few weeks, and that she should then return to town and place herself under my care.

It was not for some months that $I$ again saw this lady. It appears that after leaving town, her belief in the existence of a hitherto undiscovered cause for her sufferings became staogered, and she began to think that it was next to impossible that so many different practitioners, previously consulted, could be wrong. The persistance of all the symptoms, nevertheless, again drove her to town towards autumn. She determined, however, to seek for corroboration of my opinion. She accordingly consulted an experienced accoucheur, told him that she had been suffering for many years from uterine hæmorrhage- that she had been treated for inflammation without beneficial results - that she fancied there might be more than had been discovered by her previous attendantssome tumour or ulceration; and that she wished him to examine her with the speculum. This was accordingly done. A careful speculum examination was made, and the patient told that she had neither tumour nor ulceration, and that her disease was merely retroversion of the uterus. Simpson's probe was introduced into the cervix, and the uterus brought, as it was stated, into its right place. She was likewise told, that if this operation was repeated at proper intervals for a sufficient length of time, the vitiated direction of the organ would beremedied, and that she would recover her health.

A few days afterwards I was sent for, and frankly acquainted with what had occurred. The lady stated, however, that she had no confidence in the opinion last given, because the examination was made in such a manner as to convinee her that but little information could have been obtained. She was examined, it appears, on her side, in the usual obstetric position, on a sofa away from the window, a conical or cylindrical speculum being used, and artificial light resorted to. I had examined her, as I generally do, reclining on the back, in a strong natural light, opposite a window. I was so much surprised to hear that a careful examination had been made by a very competent person, and no tumour found, that I concluded the polypus had fallen off, by ulceration of the pedicle-a circumstance which $I$ have known to occur. To my astonishment, however, on separating the blades of the speculum, I found the small vascular tumour lying in the os, surrounded by a ring of ulceration just as before. It became evident, therefore, first, that the practitioner last consulted could not have been aware that an open fungous os uteri indicated ulceration; secondly, that by the use of the conical or cylindrical speculum, the hypertrophied lips of the cervix had been so approximated as to cover the os uteri and conceal the polypus and ulcerated surface.

By means of a pair of speculum forceps with a very small serrated extremity, I broke down, and brought away by torsion, the small tumour, and the greater part of its pedicle. A few drops of blood only were lost. I subsequently cauterized the ulccrated surface, which appeared to extend to the entire depth and circumference of the cavity of the uterine neck.

From this time forward the case resolved itself into one of inflammation and hypertrophy of the cervix, along with deepseated nlceration; and was treated by the means which $I$ usually employ-cauterization at variable intervals, emollient or astringent vaginal injections, hip-baths, leeches to the inflamed cervix, and rest in the recumbent position. Both the inflammation and ulceration, however, proved very rebellious to treatment. It was only by very slow degrees that the inflammation and hypertrophy of the lips of the cervix subsided. As this latter change occurred, the cervix, which, as I have stated, was very low and retroverted, gradually rose in the pelvis, and reassumed a more normal direction; and the ulceration likewise began to cicatrize. All that part of the ulceration external to the cavity of the os healed in the course of a few weeks, but the internal ulceration proved very obstinate, and the more so the deeper it was situated. It was only after six months' nearly continued treatment that the cavity of the cervix was completely healed. As it cicatrized it closed, until, from being long sufficiently open for an inch in depth to admit a large-sized drawing pencil, it became so contracted as merely to admit the nterine sound. For the last six weeks of the treatment, the ulceration appeared limited to a small deep-seated surface, probably that from which the polypus sprung, near the inner orifice of the cavity of the uterine neck. In order not to destroy the cicntrix of the healed part, in passing caustic up to the ulcerated surface, I used small silver tubes, half an inch in length, which $I$ fixed in the os uteri, and pushed in the requisite depth. The canstic used, always a fluid one, was passed through this tube. When the eye could no longer reach the parts still ulcerated, I judged of its continued. existence by the oozing of pus from the lips of the os uteri, and of bloo: 1 from the surface affected, on its being touched with the uterine probe. At the time the local treatment was thus brought to a close, (last March,) the cervix was at least two inches higher in the pelvis than when $I$ extixpated the polypus. It was also very much smaller, very much less retroverted, and presented no evidence of inflammatory induration, although still rather larger and harder than natural. The vagina was quite healthy. All the uterine organs were very sensible to the tonch; but in this respect they merely participated in an exaggerated state of nervous sensibility of the entire economy. Lver since the evulsion of the polypus, there had been no continued sanguineous discharge after the monthly periods, although the purulent discharge was often streaked with blood, especially after cauterization. The menses flowed five or six days rather abundantly, and were then replaced by the purulent or sanguineo-purulent discharge from the ulcer.

The slowness of the process of cicatrization in this case may be accounted for by two circumstances,-first, by the very lengthened existence which I feel warranted in ascribing to the ulceration; secondly, to the extremely debilitated state of the general health, depraved by fifteen years' flooding and suffering. Not only was the patient so reduced by the continued loss of blood, morbid and artificial, that loud anæemic murmurs were heard in the heart, and in the large bloodvessels; but the digestive and nervous system had received a very severe shock. The stomach could scarcely bear even the very lightest food, and that only in very smail quantities; the action of the bowels was irregular; they were often relaxed and irritable; and no dietetic, stimulant, or medicinal tonic, could be borne. She had been salivated more than once, and attributed this extreme susceptibility of the digestive system partly to this cause. Iron, quinine, iodine, \&c., were all tried at various periods, but as often suspended from the disturbance they created in the economy. The intercostal, the sciatic, the crural, and the dorsal and other nerves, were all, at different times, the seat of severe neuralgic pains, which generally proved rebellious to local therapeutic agents. They seemed to change their seat, or disappear under the influence of atmospheric variations, or mental or bodily conditions of a still less tangible nature, and were evidently the result of the general anæmic state of the economy.

This patient had for some years, she said, been in so excitable and sensitive a state, as not to be able to bear the operation of any medicinal substance, and had latterly entirely given up taking any. This state of the system improved considerably whilst she was under me, although she was scarcely conscious of the fact. When she left town, however, she was still very weak and debilitated, and there was still an anæmic murmur in the large vessels. She had, likewise, still pain in the back and ovarian regions; but as nearly every other part of the body was likewise the seat of neuralgic pains, I did not attach much importance to their apparent persistence. They were, however, she herself stated, much less intense than formerly. The bearing-down sensation had nearly entirely disappeared. A month after her departure from town I again had an opportunity of examining the state of the uterus. I found the os quite closed, the cervix still smaller, and all evidence of internal ulceration gone. She had been nearly entirely free from any show of blood, except during the monthly period, which passed off easily. Subsequently to my examination, however, ten days' extra exertion were followed by a very slight sanguinolent discharge from the uterus, showing that the entirely disappeared.

Remarks.-In the above case there are several points more especially deserving of notice. One of the most important is the connexion of the tumour which I found with the symptoms which the lady had suffered for so many years. There can be no doubt in my mind that the hæmorrhage which she experienced in America was owing to the existence of the 
polypus, then concealed, however, within the cavity of the cervix. Hæmorrhage at the monthly periods is one of the most prominent and most universal symptoms of uterine polypi, and occurs with the smallest polypi, as well as with the larger ones. In the course of time, no doubt, the polypus occasioned inflammation and nlceration of the mucous surfaces with which it was in contact-thus giving rise to all the symptoms which are produced by inflammatory ulceration of the cervix uteri. As I have already stated, I firmly believe that the production of such ulcerations is very frequently, if not generally, the result of the presence of polypi issuing from the os uteri; so that the practitioner has, in most cases, $\boldsymbol{t} w 0$ diseases to treat, - the uterine tumour, and the inflammation and ulceration produced by it. In the case which I have just narrated, the ulcerative inflammation may be considered as important an element in the disease as the polypoid tumour, if we judge by the reaction which they each produced on the economy. The polypus debilitates the system by the continued losses of blood which its presence occasions; but the ulcerative inflammation has an equally pernicious effect on the processes of assimilation and nutrition, tlirough the sympathetic reaction which it produces.

Although, as this case shows, the additional existence of ulcerative inflammation is of extreme importance in the history of uterine tumours, it is, as yet, I may say, generally unknown to the profession. It is not even alluded to in a recent able work, written, ex professo, on Uterine Tumours, by Mr. Safford Lee, and is not mentioned by any writer that I am acquainted with,always excepting the recent able article of Dr. Montgomery.

In the case of my patient, the polypus would appear to have taken some years to work its way to the orifice of the os. It was no doubt the dilatation of the 0 s, and the soft sensation produced by the apex of the vascular growth, that made one of this lady's medical attendants think that cancerous degenerescence was imminent. Her first attendant finding, on his arrival in England, the cervix, which he had formerly known hard, then extremely soft, and the patient. blanched by the continued depletion resorted to, concluded that the softening and opening of the os was the result of the treatment adopted. He tells me, that at that period depletion had been carried to such an extent, that she was like a person in the last stage of chlorosis, and that the blood which came from her was nearly all serum.

The extreme irritability of the nervous system, and the nervous pains noticed in this case, are not at all extraordinary. It is what we meet with continually in cases of great anæmia and physical exhaustion, whatever may be the cause. The most curious feature, however, in the history of the patient, is the fact of the existence of the tumour not having been recognised during the many years she was under medical treatment. The last error shows, that even instrumental examination does not always convey information, if imperfectly carried out. It would never have been committed, had the practitioner who made the examination used a bivalve speculum, when he found that the os uteri was open and fungons, so as to separate the lips, and to examine the cavity of the os. This is a precaution which should always be taken when the os appears open to the touch, and there is consequently reason to believe, that the cavity of the cervix is diseased. Cylindrical and conical spicula of the ordinary size do not always open the os sufficiently to admit of the eye penetrating into its cavity, and should not, consequently, be exclusively used in such cases. Indeed, no one speculum will answer for all cases, some requiring one size or form, and some another size or form. No artificial light, eithor, is equal to the full light of early day; and that position is best which best enables you to throw the daylight on to the structure examined, without any reflectors or other artificial assistance.

The general health of my patient, although evidently improved, was not restored when she lett town, notwithstanding the eradication of the nterine disease. At this we cannot be surprised, when we consider that she had been suffering from a severe debilitating disease during a great part of her existence. It is, however, my conviction, from past experience of such cases, now that the thorn has been withdrawn from her system, now that the incubus of actual disease has been removed, the economy will gradnally recover its tone under good management, hygienic and medicinal; and that she will yet live to enjoy an amount of health which slie has not known since her youth. It is not all to cure a disease that has been undermining the constitution for years; time must bo subsequently allowed to admit of Nature's rallying.

Cambridge-square, Hyde-park, June, $18 \% 7$.
ON THE USE OF ETHER IN NATURAL LABOUR.

\section{BY J. G. LANSDOW N, M.R.C.S.E.,}

SURGEON TO THE BRISTOL GENERAL HOSPITAL.

From what I saw of the effects of the ether in the case of turning, as reported in THE LANCET of April 24th, I resolved to nse it in natural labours, fully confident, not only that it would not check the accustomed action of the uterus during the process of parturition, but that it would materially expedite the delivery of the child, and that the mother would be relieved from the suffering usually attendant upon its immediate expulsion. The views I then formed of the result of its action have been fully borne out in two cases in which I have administered it. Mrs. O- was taken in labour May 7 th, with her sixth child. With her first she went the full period of gestation, and at her delivery she had an exceedingly painful time; with the four succeeding ones she went only seven months, and with each had a less painful and more speedy delivery; upon this occasion she had gone her full period, and was consequently dreading a repetition of her first painful time; against this I held out hopes of relief, which the result proved I was justified in doing. I was summoned to her at a quarter to fire P.M. Upon examination I found the labour progressing favourably; head presentation; cs uteri dilated to the size of half a crown, her pains returning about every five minutes; from half-past six they were so sharp that she began to cry out for help from the nurse and myself; at half-past seven I commenced to give her the ether at the approach of a pain; for nearly ten minutes, as often as she inhaled, an irritable cough was the result; she would then quickly withdraw the pipe and again replace it to her mouth. During this period $I$ allowed but little vapour to escape from the bladder, and her mostrils were free; at length I desisted from persevering with its use, but of her own accord she said, that as she had not felt pain while taking the ether, she preferred the cough to the pains. From this time forward she had no return of the cough; at the approach of every pain she asked for her pipe, as she called it, and slept during the time of each contraction of the uterus, her consciousness returning about half a minute after each had ceased, and continuing for three minutes; the contractions of the uterus were sometimes very considerable, so that she caught tight hold of her nurse or friend during their continuance, at the same time pressing her feet firmly against the bed-post, and pushing her body up higher on the bed, yet upon her awaking slie said she had felt no pain, nor was she conscious of any effort being made on her part; the head was much longer in its descent than I had anticipated it would have been, the child not being born until twenty-five minutes past ten, nearly three hours from the commencement of the inhalation, during which time she felt no pain nor any inconvenience after the cough had ceased; at the last the head came down with a rush, but the perimæum was fully prepared for it, being in a perfectly relaxed state ten minutes atter the birth of the child the placenta came away; there was no fluid discharge either accompanying or following the expulsion of the placenta; the nterus contracted immediately. I did not feel her pulse during the time she was under the influence of the ether, but subsequently to the birth I found it 84 . According to her own expression, the ether refreshed her and kept up her strength, so that she was quite cheerful, instead of dreading the approach of each pain, as she had been previously doing. During the progress of the labour she was perfectly cool, not requiring her face to be wiped, neither was there more than her usual colour upon her cheeks.

May 9th.-Going on well; has had no after-pains, from which, pon former occasions, she had suffered very much.

12 th.-Found my patient up; she said she was so well it was useless her lying in bed any longer.

Mrs. T-, aged thirty-five; pregnant with her eighth child; with her last three she had such profuse hamorrhage immediately following the expulsion of the placenta, that it was with great difficulty her life was preserved.

Oct. $30 \mathrm{th}, 1846$. - I was called to her, as it was supposed she had miscarried; the discharge was very considerable; she had last menstruated in the middle of August; there was no coagulum of any kind passed away; the discharge continued at intervals for a month; the pregnancy progressed to its full period, and I was sent for May 16 th ten 1 . I was then informed that labour-pains had commenced the day previous, about mid-day, but had passed off in an hour or two, and had not returned until this morning; during the first twenty minutes $I$ was there she had four pains; the os uteri was dilated to the size of a shiling; the pains then abated in fre- 